\section{OPEN ACCESS}

Edited by:

Stéphane Joost,

École Polytechnique Fédérale de Lausanne, Switzerland

Reviewed by:

Brian J. Wilsey,

lowa State University, United States

David Jack Coates,

Department of Biodiversity,

Conservation and Attractions (DBCA),

Australia

Chrisophe François Randin,

Université de Lausanne, Switzerland

${ }^{*}$ Correspondence:

Laura Lukens

Ilukens@monarchjointventure.org luke0063@umn.edu Kyle Kasten

kkasten@monarchjointventure.org

Specialty section:

This article was submitted to Conservation,

a section of the journal

Frontiers in Ecology and Evolution

Received: 31 December 2018

Accepted: 16 January 2020

Published: 06 February 2020

Citation:

Lukens L, Kasten K, Stenoien C,

Cariveau A, Caldwell W and

Oberhauser K (2020) Monarch

Habitat in Conservation Grasslands.

Front. Ecol. Evol. 8:13.

doi: 10.3389/fevo.2020.00013

\title{
Monarch Habitat in Conservation Grasslands
}

\author{
Laura Lukens ${ }^{1,2 *}$, Kyle Kasten ${ }^{1,2 *}$, Carl Stenoien ${ }^{3}$, Alison Cariveau ${ }^{1,2}$, Wendy Caldwell ${ }^{1,2}$ \\ and Karen Oberhauser ${ }^{2,4}$

\begin{abstract}
${ }^{1}$ Monarch Joint Venture, St. Paul, MN, United States, ${ }^{2}$ Department of Fisheries, Wildlife and Conservation Biology, University of Minnesota, St. Paul, MN, United States, ${ }^{3}$ Department of Entomology, University of Minnesota, St. Paul, MN, United States, ${ }^{4}$ Arboretum, University of Wisconsin-Madison, Madison, WI, United States
\end{abstract}

There is strong evidence that a major driver of the decline of eastern North American monarch butterflies (Danaus plexippus) is the loss of breeding habitat in the upper midwestern United States. Grasslands, including conservation areas, provide some of the largest remaining tracts of breeding habitat available to monarchs. While grassland conservation has been well-studied, little is known about how monarchs interact with these areas, or how planting and management practices impact the quality of habitat for monarchs. Here, we evaluate monarch habitat and use by monarchs in 61 conservation grasslands (including restoration sites in the U.S. Department of Agriculture Conservation Reserve Program, U.S. Fish and Wildlife Service Partners for Fish and Wildlife Program, and privately funded restored prairies) in Minnesota, Wisconsin, and lowa. We documented milkweed (Asclepias spp.) density and diversity, blooming plant frequency and richness, and immature monarch density during the monarch breeding seasons of 2016 and 2017, along with seeding and management histories. Milkweed was observed at 60 of 61 study sites with a mean density of 1,390 plants per hectare (median $=783$ ), a greater density than previously estimated in conservation grasslands. Monarchs were observed at 57 of 61 sites. Asclepias syriaca was the most frequently observed species, regardless of whether it was planted. Asclepias tuberosa and Asclepias incarnata may be the most cost-effective milkweeds to seed in our study geography, given that they were both more likely to be present and occurred at higher densities when planted than when not planted. Forb establishment rate varied across species planted and seeding rates. Increased rates of forb establishment were observed at larger sites, sites planted in the fall, and sites with fewer species in the seed mix. We observed a relatively low frequency of early season nectar sources, suggesting that managers should consider including more early blooming species in seed mixes and on existing conservation lands. We present establishment information for consideration in seed mix design and describe how our findings can be used to inform monarch habitat availability models, future studies, and conservation efforts.

Keywords: monarch butterfly, Danaus plexippus, milkweed, Asclepias, nectar plants, habitat monitoring, habitat management, prairie reconstruction 


\section{INTRODUCTION}

The decline of the eastern migratory North American monarch butterfly (Danaus plexippus) population has been well documented (Brower et al., 2012; Rendon-Salinas et al., 2018). Annual population estimates in the overwintering sites in Mexico have revealed a steep decline in the area occupied by monarchs over the last two decades (Rendon-Salinas et al., 2018). Measurements of egg density in the northern United States suggest a similar trend during the summer breeding season (Stenoien et al., 2015). Projection models suggest that the monarch decline is worrisome enough to predict a monarch quasi-extinction probability of $11-57 \%$ over the next 20 years (Semmens et al., 2016).

While eastern monarchs experience many threats throughout their annual migration cycle, research suggests that a main cause of their population decline is the loss of breeding habitat in the Upper Midwest of the United States (Semmens et al., 2016; Pleasants et al., 2017; Thogmartin et al., 2017a). Monarch larvae consume plants in the genus Asclepias (and a few closely related genera), commonly known as milkweeds. Twenty years ago, a significant portion of monarchs originating in the Upper Midwest utilized milkweed found in agricultural habitats (Oberhauser et al., 2001). Since the introduction of genetically modified herbicide-tolerant row crops (corn and soybeans), milkweed within these crop fields has largely disappeared, significantly reducing the availability of monarch host plants in agricultural settings (Hartzler, 2010; Pleasants and Oberhauser, 2012; Stenoien et al., 2016; Thogmartin et al., 2017b).

Nectar resources are also an important component of monarch habitat. More than $99 \%$ of native northern tallgrass prairie has been lost since European settlement, and with it, many of the nectar resources that previously existed in these habitats (Samson and Knopf, 1994). Lark et al. (2015) estimate that 5.7 million acres of grassland in the U.S. were converted to cropland from 2008 to 2012, accounting for $77 \%$ of the overall cropland conversion during that time. This, coupled with the loss of milkweed in agricultural fields, has made monarch breeding habitat increasingly rare in much of their eastern breeding range (Pleasants, 2017).

Current population viability models estimate that 1.31.6 billion milkweed stems need to be added throughout the eastern migratory range to bring the eastern migratory monarch population back to a sustainable level (Pleasants, 2017; Thogmartin et al., 2017a). Many habitat conservation or restoration initiatives, including programs like the U.S. Department of Agriculture Farm Service Agency's Conservation Reserve Program (CRP), are being engaged to help reach this habitat target. Despite conservation activities already being implemented, there have been few studies to examine the quality of restored or conserved habitats for monarchs, or how monarchs are using those habitats. Since conservation practitioners rely on a variety of pre- and post-planting tools and methodologies for a successful habitat project, understanding how these factors interact is critical to guiding future monarch habitat conservation activities.
Here, we (1) provide metrics of monarch habitat and use by monarchs in midwestern conservation grasslands and (2) investigate factors important for developing and maintaining monarch habitat and monarch use, including seeding and other management practices. We used an observational approach to address the following questions regarding the establishment and availability of milkweeds and blooming nectar plants, the defining features of monarch butterfly breeding habitat. What is the availability of milkweeds and blooming plants in these conservation grasslands and how do these metrics vary within growing seasons? For each milkweed species, is its inclusion in the seed mix or its seeding rate predictive of its establishment and density? How do seed mix characteristics (diversity and seeding rates), site age, planting season, and other management actions influence the frequency and establishment of milkweeds and blooming plants? Finally, are any site characteristics predictive of immature monarch abundance? Addressing these questions will inform monarch population and habitat modeling, land management decisions, as well as continued research on the importance of conservation lands for supporting monarchs and other pollinators.

\section{MATERIALS AND METHODS}

\section{Site Selection}

We surveyed 61 conservation sites in Minnesota, Wisconsin, and Iowa during the growing seasons of $2016(n=23)$ and $2017(n=38)$ (Figure 1). Landowner and manager participants were recruited through outreach from local conservation offices, researchers, and other conservation stakeholders. Thirty nine sites were enrolled in CRP, 10 were part of the U.S. Fish and Wildlife Service Partners for Fish and Wildlife Program, and 12 were privately funded native prairie restorations that were not enrolled in formal conservation programs. Prior to restoration or conservation practices, most sites $(n=46)$ were used for row-crop agriculture, primarily corn or soybeans. Other previous land-use types included agricultural conservation land (expired WRP and CRP parcels, $n=4)$, pasture $(n=2)$, unmanaged grassland $(n=2)$, and remnant prairie $(n=1)$. The remaining six sites did not have information on previous use. All sites were seeded except for the remnant prairie and one unmanaged grassland. Time since seeding (site age) ranged from 1 to 32 years $($ mean $=8.4$, median $=6$ ), based on the most recent seeding of the entire site area, and size ranged from 1 to 38 hectares $($ mean $=11$, median $=7$ ).

\section{Field Survey Methods}

Field sampling procedures followed the Integrated Monarch Monitoring Program (2017 version) (Commision for Environmental Cooperation, 2017; Cariveau et al., 2019a). Sites were surveyed 3-5 times during the monarch breeding season (May-September), with crews examining $1501 \mathrm{~m}^{2}$ quadrats $(0.5 \mathrm{~m} \times 2.0 \mathrm{~m})$ placed $7 \mathrm{~m}$ apart along a series of parallel transects during each visit. The number of transects varied depending on site dimensions and size, and placement 


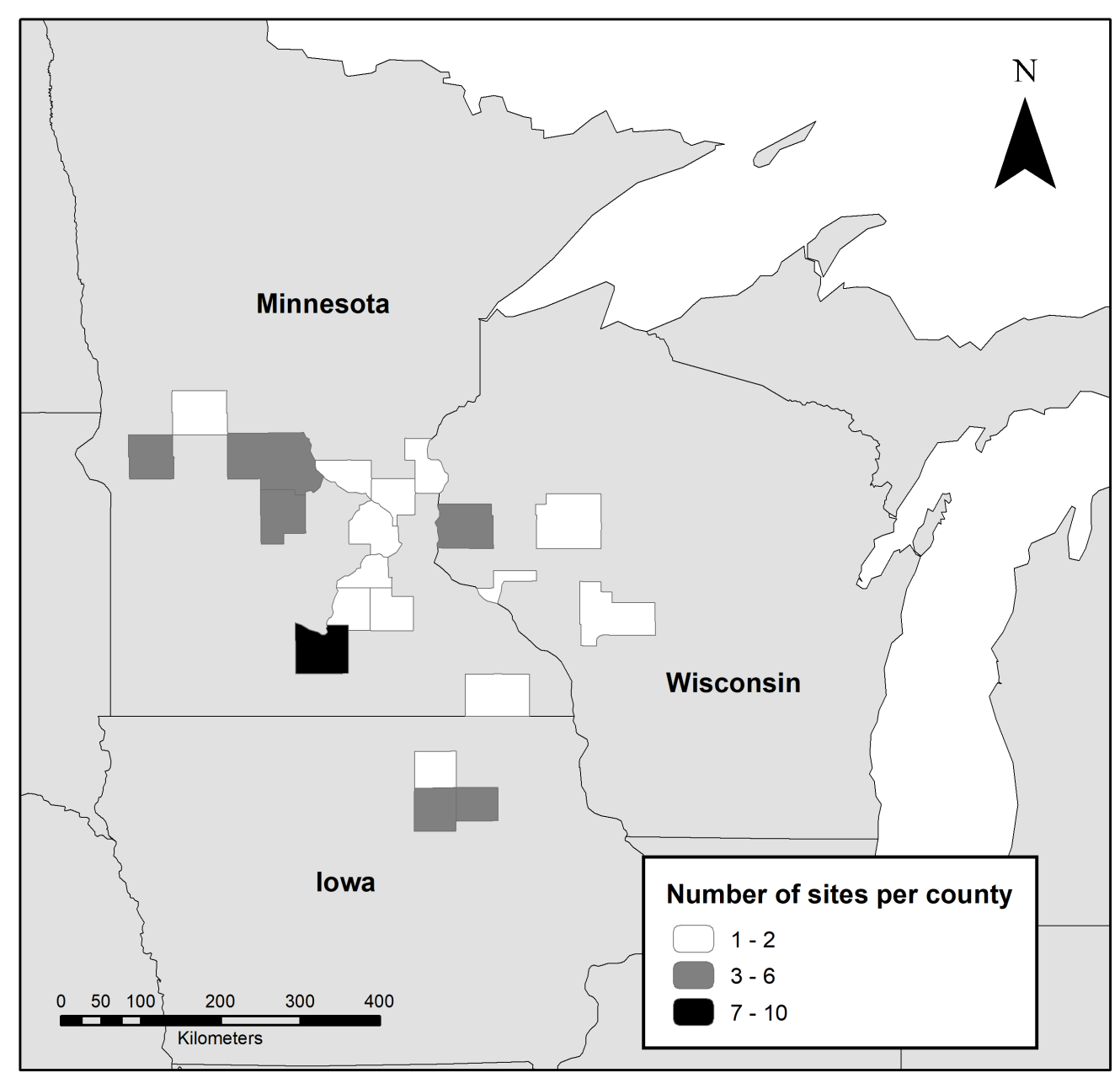

FIGURE 1 | Location of study sites surveyed for monarchs, milkweed, and blooming plants during 2016 and 2017 by county.

and orientation were randomized for each visit using Geographic Information Systems software (ESRI, 2011).

The following data were collected on milkweeds, blooming plants, and monarchs:

(1) Milkweed density and species richness: Within each quadrat, the number of milkweed plants by species was recorded. Milkweed stems separated by soil were recorded as distinct plants, regardless of whether they were clonal or genetic individuals (following Kasten et al., 2016; Commision for Environmental Cooperation, 2017; Cariveau et al., 2019a). Following the quadrat survey, a meandering walk survey was conducted to check for additional milkweed species not observed in quadrats to accurately capture species diversity at each site.

(2) Blooming plant frequency and species richness: Three nested sections within quadrats aided in frequency sampling for blooming plants (Elzinga et al., 1998). The presence of blooming plant species was recorded within each quadrat, with blooming defined as having at least one flower open. Opportunistic observations of blooming plant species found outside of quadrats (but within the site boundaries) were recorded separately during quadrat sampling and during the meandering walk survey completed afterward. Data collected in the meandering survey were only used to supplement a species list for each site. Such methodology is useful for detecting rare species that would be less likely to occur in the quadrats (Szigeti et al., 2016; Larson et al., 2018).

(3) Monarch egg and larva per milkweed plant density: Each milkweed plant within quadrats was searched for the presence of monarch eggs and larvae. To increase the number of plants sampled, milkweed plants between quadrats and within $1 \mathrm{~m}$ of each side of the transect line were also searched. After a total of 100 milkweed plants had been examined, only milkweeds within quadrats were searched.

(4) Incidental adult monarchs: Opportunistic sightings of adult monarchs were recorded while surveying each site. If observed nectaring, the nectar plant species was also identified. 


\section{Seeding and Management History}

Landowners or managers provided seeding and management data for each site to identify characteristics that could have influenced milkweed and blooming plant establishment. Seed quantities were reported in one of three units: pure live seed (PLS), bulk, or number of plugs. PLS, referring to the amount of viable seed, provides greater reliability in comparing across seed mixes (Englert, 2007; Houck, 2009), and therefore only sites that reported PLS were used in our seed rate analyses $(n=19)$. Landowners and managers reported using a combination of management practices, including prescribed burning, mowing, and herbicide use. Because all sites had been mowed or treated with herbicide at least once, yet detailed records of management dates and specific treatment areas were lacking from most managers, we excluded these practices from our analyses. Dates of prescribed burns were known for 55 of the 61 sites; 35 sites were burned at least once since planting (mean number of burns $=1.23$, median $=1$, range $=0-6$ ).

\section{Data Analysis}

All statistical tests were performed in $\mathrm{R}$ version 3.5.1 ( $\mathrm{R}$ Core Team, 2018). We excluded Asclepias verticillata (whorled milkweed) from all milkweed density analyses because its growth form and biomass are very different from the other species observed (small statured, dense clusters of stems), and because it was not included in models used to generate milkweed density targets (Thogmartin et al., 2017a). Blooming plant frequency was calculated as the proportion of subplots occupied by blooming plants. We calculated this in three ways: (1) the frequency of each forb species independently, (2) the total frequency of all planted forb species at a site, and 3) the frequency of all forb species at a site including those not planted. Blooming plant establishment rate refers to the proportion of forb species planted that were observed blooming at each site. Milkweed establishment rate refers to the proportion of sites in which a planted species of milkweed was observed. Milkweed colonization rate refers to the proportion of sites in which a species was observed but not planted. Immature monarch density is reported as the sum of the eggs and larvae divided by the number of milkweed plants examined.

We used Fisher Exact Tests to compare the establishment and colonization of the four milkweed species observed, and Kruskal-Wallis tests to determine whether planting milkweed seeds led to greater observed densities. Linear models were used to examine the effect of milkweed seeding rates on observed milkweed density.

To assess the effect of the time of sampling on milkweed density and the frequency of planted blooming species, we built two linear mixed-effects models (lme4 package) (Bates et al., 2015). In these models, we used the ordinal day of visit, with site ID as a random effect, as predictor variables. Date of sampling was treated as a second order polynomial variable because we predicted that milkweed density and blooming plant frequency would have curvilinear relationships with time. Sites at which milkweeds were never detected were excluded from the milkweed density analysis.
We used a two-step process to examine the effects of several predictors on four response variables of interest: milkweed density, blooming plant frequency (planted forb species only), blooming plant establishment rate, and immature monarch density. First, we built multivariate linear regression models using the lmer function in $\mathrm{R}$, including the factors we hypothesized to be most important (Tables 1A,B) (lme4 package, Bates et al., 2015). We used generalized linear regression models (GLMs) with a binomial distribution and logit link function for blooming plant frequency and establishment rate. Next, we performed backwards model selection by AIC value using the MASS package step function to identify the relationship between each set of predictors and response variables (Venables and Ripley, 2002).

In these models, milkweed density, blooming plant frequency, and immature monarch density were averaged across visits for each site. We log-transformed milkweed density and immature monarch density to normalize the error terms of these otherwise right-skewed response variables. Site visits in which milkweeds were not detected were excluded from the immature monarch density model. Response variables were visually inspected for egregious outliers, and one site was removed from milkweed models because it had a milkweed density three times greater than the next largest value. Because only two sites were seeded during winter and one of them was never seeded with forbs (only grasses), we excluded winter plantings from all models. Two sites (the remnant prairie and existing grassland) were also excluded since they were never seeded, and therefore, age values were null.

Using Pearson's product moment correlation, we examined the correlation between site age, forb seeding rate, and number of planted forb species. We also examined the relationship between planting season and site age, and the relationship between planting season and forb seeding rate with ANOVA and Tukey's HSD. We considered them significantly correlated if $p \leq 0.05$. Variables with statistically significant correlations were included as interactions in each model.

Due to limited sample sizes, burning frequency and forb seeding rate were examined univariately with each response variable. Because a significant portion of our study sites were younger than 3 years old and because plantings are not typically burned until the third or fourth year, we only included sites that were older than 3 years in the burning models $(n=30)$. Burning frequency was calculated as the total number of entire site burns divided by site age. Only sites that included seeding rate information in PLS were included in forb seeding rate analyses $(n=27)$.

\section{RESULTS}

\section{Milkweed}

Across sites, we observed four milkweed species: Asclepias syriaca (common milkweed), A. incarnata (swamp milkweed), A. tuberosa (butterfly milkweed), and A. verticillata (whorled milkweed). At least one milkweed plant was observed at 60 of 61 study sites. Total milkweed density (A. syriaca, A. incarnata, 
TABLE 1 | (A) Planting and post-planting management variables included in analyses of milkweed density, blooming plant frequency (planted forb species only), and blooming plant establishment rate. (B) Predictor variables included in immature monarch density analysis.

\begin{tabular}{|c|c|c|c|c|c|}
\hline Predictor variables & $\begin{array}{l}\text { Response } \\
\text { variable }\end{array}$ & Rationale & References & Mean & Range \\
\hline \multicolumn{6}{|l|}{ (A) } \\
\hline $\begin{array}{l}\text { Site age: time since } \\
\text { planting (years) }\end{array}$ & All & $\begin{array}{l}\text { Outcome variables could change over } \\
\text { time }\end{array}$ & Middleton et al., 2010 & 8 & $1-29$ \\
\hline Site size (ha) & All & Larger areas could harbor more species & Grman et al., 2015 & 10.858 & $1.129-37.969$ \\
\hline $\begin{array}{l}\text { Season in which site was } \\
\text { planted }\end{array}$ & All & $\begin{array}{l}\text { Planting season may influence } \\
\text { blooming plant community } \\
\text { establishment }\end{array}$ & Larson et al., 2011, 2017 & $\begin{array}{l}\text { Spring (most } \\
\text { common) }\end{array}$ & NA \\
\hline $\begin{array}{l}\text { Seeding rate, PLS (kg/ha) } \\
\text { (milkweed, forbs) }\end{array}$ & All & $\begin{array}{l}\text { High seeding densities may enhance } \\
\text { the establishment of some species }\end{array}$ & Dickson and Busby, 2009 & $\begin{array}{l}\text { Milkweed: } \\
0.069 \text {, forbs: } \\
1.446\end{array}$ & $\begin{array}{l}\text { Milkweed: } \\
\text { 0-0.702 forbs: } \\
0.076-3.537\end{array}$ \\
\hline $\begin{array}{l}\text { Number of forb species } \\
\text { planted }\end{array}$ & $\begin{array}{l}\text { Blooming plant } \\
\text { establishment rate, } \\
\text { frequency }\end{array}$ & $\begin{array}{l}\text { More species could increase } \\
\text { competition }\end{array}$ & Carter and Blair, 2012 & 29 & $4-64$ \\
\hline $\begin{array}{l}\text { Index of prescribed burn } \\
\text { frequency (inverse of } \\
\text { average number of years } \\
\text { between entire burns) }\end{array}$ & All & $\begin{array}{l}\text { Burning may encourage native } \\
\text { blooming plant establishment rate and } \\
\text { frequency }\end{array}$ & Bowles and Jones, 2013 & 0.151 & $0-0.5$ \\
\hline \multicolumn{6}{|l|}{ (B) } \\
\hline $\begin{array}{l}\text { Average milkweed density } \\
\text { at site }\end{array}$ & $\begin{array}{l}\text { Immature monarch } \\
\text { density }\end{array}$ & $\begin{array}{l}\text { Greater milkweed density may lead to } \\
\text { more immature monarchs }\end{array}$ & $\begin{array}{l}\text { Oberhauser, 2004; Kasten } \\
\text { et al., } 2016\end{array}$ & 1,419 & $0-16,880$ \\
\hline $\begin{array}{l}\text { Average blooming plant } \\
\text { richness at site (all species) }\end{array}$ & $\begin{array}{l}\text { Immature monarch } \\
\text { density }\end{array}$ & $\begin{array}{l}\text { Greater nectar plant diversity may lead } \\
\text { to increased monarch abundance }\end{array}$ & Majewska et al., 2018 & 16 & $7-27$ \\
\hline $\begin{array}{l}\text { Average blooming plant } \\
\text { frequency at site (all } \\
\text { species) }\end{array}$ & $\begin{array}{l}\text { Immature monarch } \\
\text { density }\end{array}$ & $\begin{array}{l}\text { Greater number of nectar plants may } \\
\text { lead to increased monarch abundance }\end{array}$ & Majewska et al., 2018 & 0.451 & $0.085-0.925$ \\
\hline Site size (ha) & $\begin{array}{l}\text { Immature monarch } \\
\text { density }\end{array}$ & $\begin{array}{l}\text { Movement of adults is affected by size } \\
\text { of a milkweed patch }\end{array}$ & Grant et al., 2018 & 10.858 & $1.129-37.969$ \\
\hline
\end{tabular}

TABLE 2 | Milkweed density by species across sites (plants/ha) $(n=61)$.

\begin{tabular}{|c|c|c|c|c|c|c|}
\hline & A. syriaca & A. incarnata & A. tuberosa & A. verticillata & $A / I$ & All, excluding A. verticillata \\
\hline Mean & 1212 & 129 & 50 & 473 & 1,864 & 1,390 \\
\hline Median & 717 & 0 & 0 & 0 & 1,000 & 783 \\
\hline Range & $0-16,733$ & $0-5,767$ & $0-1,217$ & $0-19,800$ & $0-19,883$ & $0-16,880$ \\
\hline
\end{tabular}

and $A$. tuberosa combined) ranged from $0-16,880$ plants/ha with a mean of 1,390 plants/ha (median $=783)$. Individual species densities are listed in Table 2.

Milkweed density varied significantly across the sampling period (Supplementary Figure S1). Based on the coefficients from the mixed-effects model, milkweed density peaked in midJuly (Supplementary Table S1).

Levels of establishment (Fisher Exact Test, $p<0.0001$ ) and colonization (Fisher Exact Test, $p<0.0001$ ) varied among milkweed species (Figure 2 and Table 3). Asclepias syriaca was observed at 24 of 25 sites in which it was planted, and at all 33 sites in which it was not planted ( $n=58$, two sites were not seeded, one site lacking seed mix data). Asclepias incarnata was observed at 12 of 14 sites in which it was planted, and 21 of 44 sites in which it was not planted. Asclepias tuberosa was observed at 14 of 25 sites where planted, and 5 of 33 in which it was not planted. Lastly, Asclepias verticillata was never observed at sites in which it was planted ( 0 of 8$)$ but was observed at 13 of 50 sites where it was not planted.
To determine whether planting any milkweed (regardless of seeding rate) leads to greater milkweed density, we compared densities based on whether a given species was planted or not (Table 3). When planted, Asclepias incarnata and A. tuberosa had significantly higher densities than when not planted, and A. verticillata and A. syriaca densities did not depend on whether they were planted. Seeding rate had a similarly varied effect on milkweed densities. When milkweed species were combined (A. syriaca, A. incarnata, and A. tuberosa), total milkweed density was significantly correlated with seeding rate $\left(F_{1,15}=12.5\right.$, $p=0.003$ ) (Figure 3A). Species-specific linear models indicated that $A$. incarnata was significantly and positively related to seeding rate $\left(F_{1,5}=7.892, p=0.038\right.$, Figure 3B $)$. Asclepias syriaca and $A$. tuberosa densities did not significantly relate to seeding rate $\left(F_{1,8}=0.208, p=0.661, F_{1,10}=0.800, p=0.392\right.$, respectively, Figures 3C,D).

After backwards model selection, seeding rate and site age were left as the best predictors of milkweed density, but neither was significant (Table 4). We did not detect any effects of 


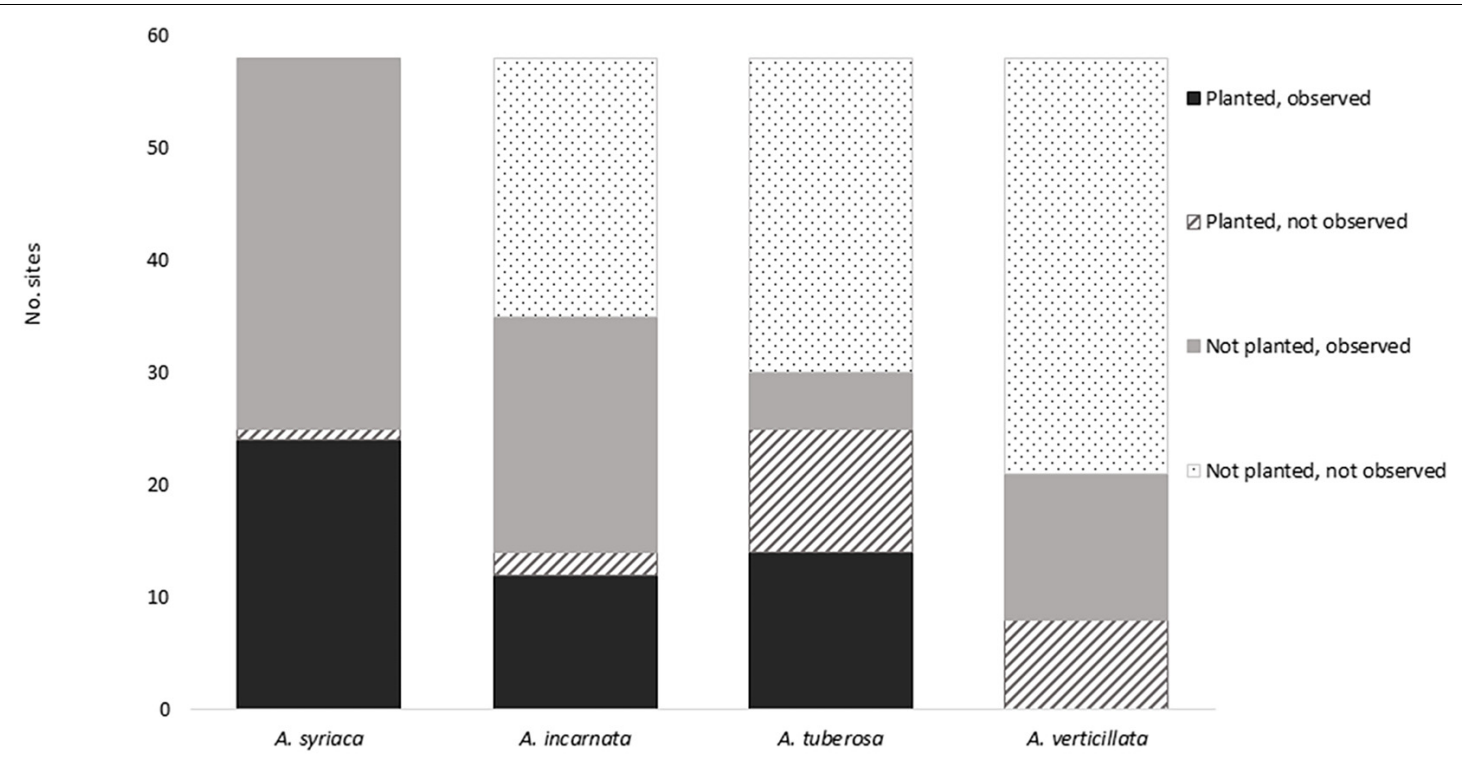

FIGURE 2 | Milkweed occurrence by species. Total number of sites = 58; seed mix data were not available for 3 of 61 sites.

TABLE 3 | Comparison of the presence and densities of milkweed species at sites where milkweeds were planted (establishment) and at sites where they were not (colonization).

\begin{tabular}{|c|c|c|c|c|c|}
\hline & & A. syriaca & A. incarnata & A. tuberosa & A. verticillata \\
\hline \multirow{3}{*}{$\begin{array}{l}\text { Question: Is milkweed more likely to be } \\
\text { present at sites where it was planted? }\end{array}$} & Establishment rate & 0.960 & 0.857 & 0.560 & 0.000 \\
\hline & Colonization rate & 1.00 & 0.477 & 0.156 & 0.260 \\
\hline & $p$-value (Fisher's Exact test) & 0.431 & $0.015^{\star}$ & $0.002^{\star}$ & 0.178 \\
\hline \multirow{3}{*}{$\begin{array}{l}\text { Question: Is milkweed density higher at } \\
\text { sites where it was planted? }\end{array}$} & Mean density when planted (plants/ha) & 1526 & 367 & 132 & 0.00 \\
\hline & Mean density when not planted (plants/ha) & 1217 & 1 & 2 & 285 \\
\hline & p-value (Kruskal-Wallis) & 0.215 & $0.029^{\star}$ & $0.015^{\star}$ & 0.365 \\
\hline
\end{tabular}

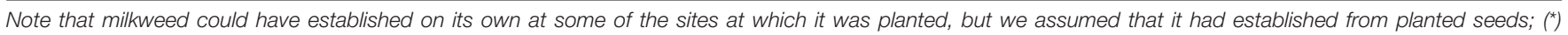
indicates significance at $\alpha=0.05$.

prescribed burn frequency on milkweed density $\left(F_{1,29}=0.069\right.$, $p=0.794)$ (Supplementary Table S3).

\section{Blooming Plant Frequency}

The average frequency of planted blooming species (those included in the seed mix) across sites was 0.29 (median $=0.20$, range $=0$-0.97). In other words, we observed planted blooming species in $29 \%$ of the $1 \mathrm{~m}^{2}$ quadrats sampled, on average, during any given site visit. The average frequency of all blooming species (including weedy and volunteer species) was 0.45 (median $=0.44$, range $=0-0.99$ ). During peak bloom for each site (the visit for each site with the highest frequency of blooming plants), the average frequency of planted species was 0.54 (median $=0.60$, range $=0.01-0.97$ ), and the average frequency of any blooming species was $0.70($ median $=0.74$, range $=0.17-0.99)$.

The frequency of planted blooming species varied significantly across the sampling period ( $p=<0.001$ ) (Supplementary Figure S2). Based on the coefficients from the mixed-effects model, blooming plant frequency at these sites peaked on August 2 (Supplementary Table S2).
Forb seeding rate was negatively correlated with site age $(p=0.01)$ and positively correlated with the number of forb species planted $(p=0.049$ ). The number of forb species planted varied across planting seasons $(p=0.014)$. More forb species were planted in fall than in spring $(p=0.011)$ but summer was not significantly different from spring or fall $(p=0.132,0.437$, respectively). Similarly, site age varied across planting seasons $(p=0.018)$. Sites that were planted in the spring were typically older than those planted in summer $(p=0.030)$. Fall plantings did not significantly differ in age from spring or summer plantings $(p=0.071, p=0.999$, respectively), nor did forb seeding rate differ across seasons $(p=0.144)$. There was a trend for higher numbers of forb species planted on more recently established sites, but the correlation was not statistically significant $(p=0.102)$.

After backwards model selection by AIC value, site age remained as the best predictor of blooming plant frequency but was not significant (Table 4). We did not detect any effect of forb seeding rate or prescribed burn frequency on blooming plant frequency ( $p=0.199, p=0.962$, respectively, Supplementary Table S3). 


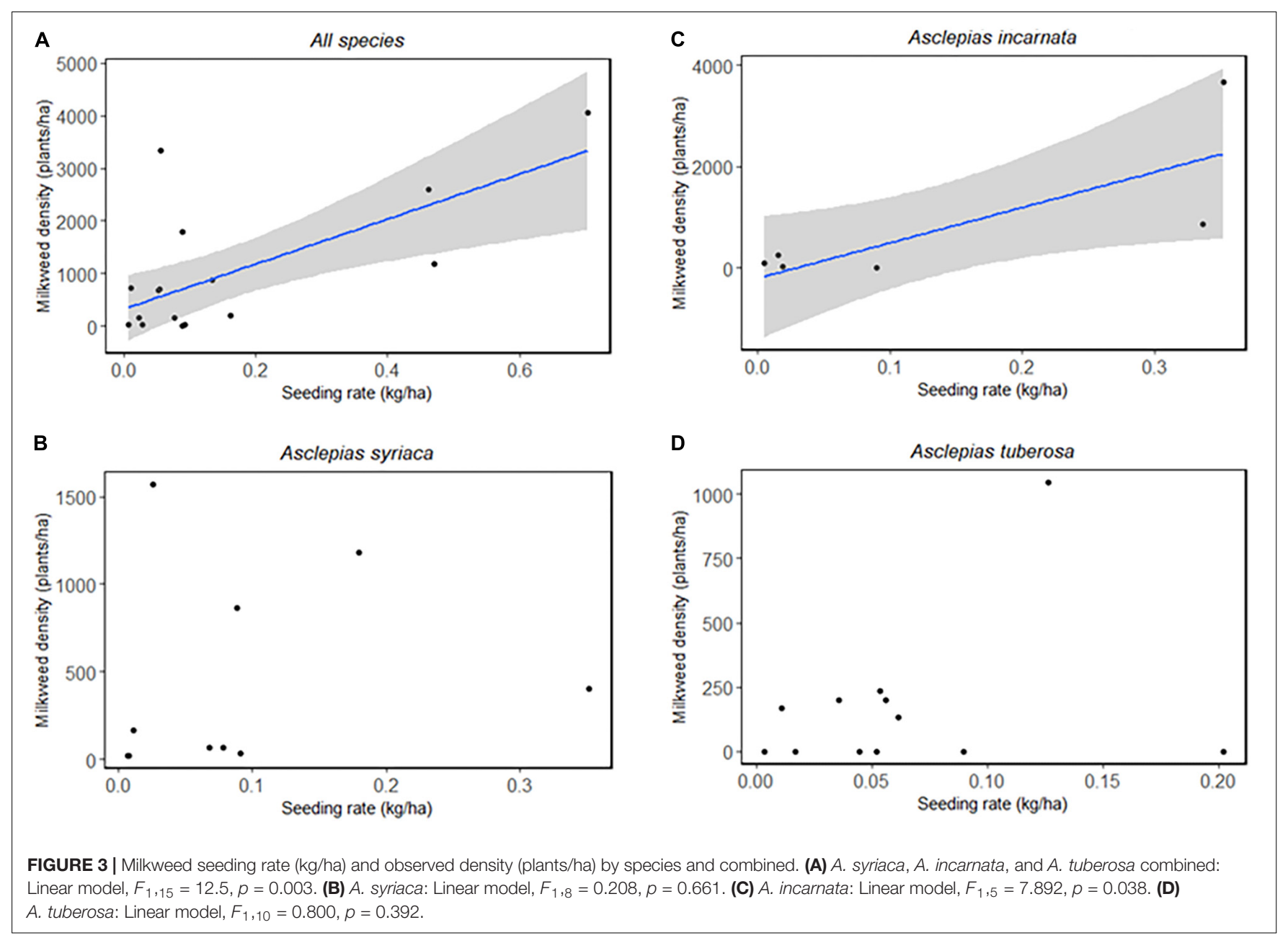

TABLE 4 | Model selection results for milkweed density, blooming plant establishment rate, blooming plant frequency, and immature monarch density.

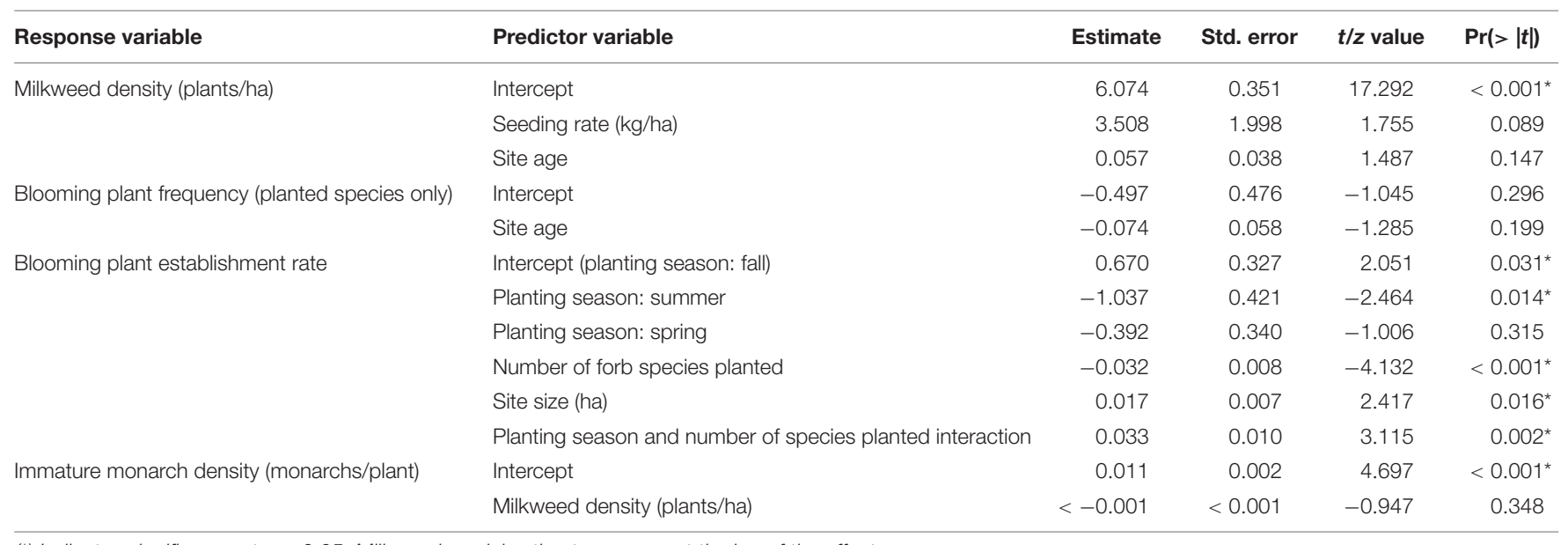

${ }^{*}$ Indicates significance at $\alpha=0.05$. Milkweed model estimates represent the log of the effect.

\section{Blooming Plant Establishment}

We documented a total of 288 blooming plant species across sites, with a mean of 36 blooming species per site (median $=34$, range $=18-80)$ and 13 planted species (median $=12$, range $=1-33)$. An average of $47 \%$ of blooming species planted at study sites were observed during sampling (median $=46 \%$, range $=21-100 \%)$. The average number of forb species included in a seed mix was 29 (median $=29$, range $=4-64)$. On average, we observed ten colonizing species per site that were not included in the mix (median $=9$, range $=0-52$ ). Erigeron annuus 
TABLE 5 | Establishment and colonization patterns of the 10 most commonly planted forbs across study sites (for all forbs, see Supplementary Table S4).

\begin{tabular}{|c|c|c|c|c|c|c|}
\hline Species & $\begin{array}{l}\text { No. sites } \\
\text { planted }\end{array}$ & $\begin{array}{l}\text { Avg PLS seeding } \\
\text { rate (kg/ha) }\end{array}$ & $\begin{array}{l}\text { No. sites observed } \\
\text { (where planted) }\end{array}$ & $\begin{array}{l}\text { Establishment } \\
\text { rate }\end{array}$ & $\begin{array}{l}\text { No. sites observed } \\
\text { (where not planted) }\end{array}$ & $\begin{array}{c}\text { Avg } \\
\text { frequency }\end{array}$ \\
\hline Dalea purpurea & 50 & $0.131, n=27$ & 38 & 0.76 & $7 / 11$ & 0.051 \\
\hline Rudbeckia hirta & 50 & $0.092, n=25$ & 50 & 1.00 & $7 / 11$ & 0.250 \\
\hline Monarda fistulosa & 46 & $0.040, n=24$ & 44 & 0.96 & $6 / 15$ & 0.224 \\
\hline Solidago rigida & 41 & $0.055, n=21$ & 21 & 0.51 & $2 / 20$ & 0.084 \\
\hline Dalea candida & 39 & $0.107, n=20$ & 26 & 0.66 & $6 / 22$ & 0.103 \\
\hline Ratibida pinnata & 39 & $0.083, n=25$ & 39 & 1.00 & $9 / 22$ & 0.250 \\
\hline Zizia aurea & 38 & $0.053, n=17$ & 23 & 0.61 & $6 / 23$ & 0.047 \\
\hline Heliopsis helianthoides & 33 & $0.087, n=14$ & 30 & 0.91 & $11 / 28$ & 0.150 \\
\hline Astragalus canadensis & 32 & $0.050, n=16$ & 11 & 0.34 & $0 / 29$ & 0.023 \\
\hline Symphyotrichum novae-angliae & 32 & $0.025, n=17$ & 9 & 0.28 & $2 / 29$ & 0.016 \\
\hline
\end{tabular}

(daisy fleabane), Cirsium arvense (Canada thistle), and Melilotus alba (white sweet clover) were among the most commonly observed colonizing species across sites (observed at 58, 49, and 38 sites, respectively; see also Supplementary Table S4).

The most commonly sown species are listed in Table 5. Rudbeckia hirta (black-eyed Susan) and Ratibida pinnata (yellow coneflower) were most successful among these species; they were observed growing at all sites in which they were planted ( $n=50, n=39$, respectively) and with the highest average frequency across sites. Astragalus canadensis (Canada milkvetch) and Symphyotrichum novae-angliae (New England aster) were least successful when planted; they were only observed at 28 and $34 \%$ of sites in which they were sown ( $n=11, n=9$, respectively), and at the lowest average frequency across sites (Table 5). Two commonly planted species, Ratibida pinnata and Astragalus canadensis, showed a positive frequency response to seeding rate while others did not (Figure 4).

After backwards model selection, the number of planted species, planting season, site size, and the interaction of number of planted species and planting season remained as the best predictors of blooming plant establishment rate (Table 4). The number of species planted was negatively related to forb establishment rate while site size was positively related to establishment rate ( $p<0.001, p=0.016$ respectively, Table 4). Sites seeded in the fall (September-November) had higher establishment rates than those seeded in the summer (JulyAugust, $p=0.031$ ) (spring plantings did not significantly differ from either other season). We did not detect any effect of forb seeding rate or prescribed burn frequency on blooming plant establishment rate $(p=0.265, p=0.173$, Supplementary Table S3).

\section{Monarch Occupancy}

Monarchs (eggs, larvae, or adults) were observed at 57 of 61 sites surveyed. At least one adult monarch was observed at 54 of 61 sites. We observed direct use of habitat including nectaring and oviposition at 34 of 61 sites; at the other sites, adult monarchs were simply observed flying over the habitat. We observed 71 adult monarchs nectaring on 31 different blooming plant species across sites. The species on which they were most frequently observed nectaring were Monarda fistulosa (wild bergamot) $(n=10)$, Asclepias spp. $(n=8)$, Liatris spp. (blazing star) $(n=7)$, and Solidago spp. (goldenrod) $(n=5)$ (Supplementary Figure S3).

Milkweed density remained as the best predictor of immature monarch density after backwards model selection but was not significantly related to monarch density ( $p=0.348$, Table 4).

\section{DISCUSSION}

\section{Milkweed}

Regardless of whether or not they were planted, milkweeds were present at almost every site we studied. This suggests that Asclepias species in general, especially A. syriaca, are good colonizers, either due to viable seeds remaining in localized natural seedbanks or by dispersal from surrounding areas. However, since the effectiveness of herbicide tolerant technology has dramatically reduced the number of milkweeds within the agricultural landscape during the last 20 years (Pleasants and Oberhauser, 2012; Stenoien et al., 2016), the potential for future recolonization could be limited because of a reduced natural seedbank. On the other hand, studies in roadsides and urban areas have document a high presence of milkweeds (Kasten et al., 2016; Cariveau et al., 2019b; Johnston et al., 2019), which could support recruitment and colonization. Thus, while colonization success could be altered given changing milkweed abundance on the landscape, our study suggests that land managers can expect some degree of milkweed colonization.

Asclepias incarnata and A. tuberosa were more likely to be present and found at higher densities when they had been planted; $A$. syriaca was equally likely to be present in sites in which it was not planted, and we did not find A. verticillata in any of the sites in which it had been planted (although it colonized approximately one fourth of sites where it was not planted). Asclepias incarnata was the only species that showed a significant positive correlation between seeding rate and density. Based on these results, A. incarnata and A. tuberosa appear to be the most costeffective milkweed species to include in seed mixes within our study geography. Additional considerations for establishing 


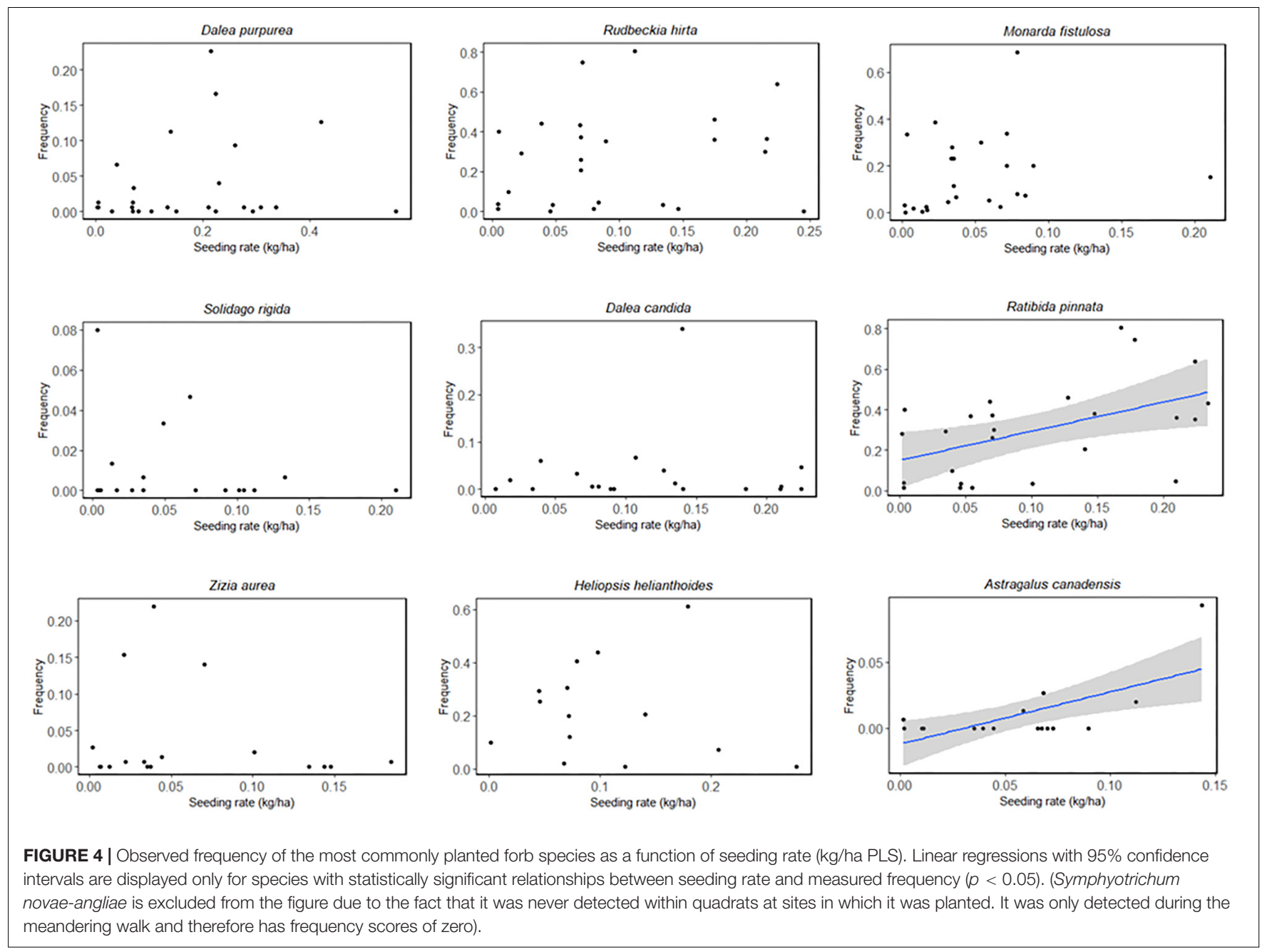

A. verticillata may be needed if it is a desired species for a conservation project.

Milkweed densities in our study sites peaked during midJuly, suggesting that monitoring efforts intending to capture peak milkweed density for similar sites in this bioregion should occur during mid-summer, after seedlings and ramets have emerged, but prior to senescence. Because milkweed density varies throughout the season, the highest densities that could be used to assess a site's contribution to national milkweed stem targets should occur mid-summer. Although we did not observe any effects of planting season, site age, or burning frequency on milkweed density, these factors may be worthy of further study, given that milkweed and monarch oviposition have been shown to respond favorably to landscape disturbance (Evetts and Burnside, 1972; Baum and Mueller, 2015; Haan and Landis, 2019).

Previous studies have estimated an average density of 277 stems per hectare in CRP lands and 8 stems per hectare in protected grasslands (Hartzler and Buhler, 2000; Hartzler, 2010; Thogmartin et al., 2017a). We observed a mean milkweed density of 1,390 plants per hectare (median $=783$ ), approximately five times higher than these previous estimates. However, given that the landowners volunteered to participate in a study of monarch habitat, it is possible that the milkweed densities in our study sites may be higher than what is present on a random sample of CRP lands or conservation grasslands. Most of the participating landowners in this study expressed a desire to conserve pollinators and wildlife in general and managed their sites for these objectives. Nevertheless, the high milkweed densities on these sites set a standard for a quality that can be achieved across conservation grasslands.

Kasten et al. (2016) found that immature monarch density is positively correlated with milkweed density up to 4,942 plants per acre in roadsides. This suggests that managing for even higher densities than we observed could benefit breeding monarchs. However, managing for highly diverse grassland habitats that are rich with timely blooming species as well as milkweed host plants will benefit many additional species.

\section{Blooming Plant Frequency and Establishment}

Previous studies have identified the importance of nectar plants as a component of monarch habitat (Stenoien et al., 2016; 
Thogmartin et al., 2017a,b; Kinkead et al., 2019), and have proposed that a loss of nectar plant resources could be a significant contributor to increased mortality during migration (Agrawal and Inamine, 2018). The general lack of data on monarch habitat as a whole (milkweed plus nectar plants) makes studies like ours even more necessary. Because nectar plants are used by many species beyond monarchs, we stress the importance of tracking and gathering data on nectar availability.

We chose frequency sampling over other options (e.g., densities or aerial cover) because it is highly repeatable across observers and field conditions, is robust across seasonal variation, and is highly efficient (Elzinga et al., 1998). This method enabled us to assess relative frequency of species included in the seed mix and to characterize the blooming plant communities at each site. To detect more rare species, we conducted a meandering walk survey following quadrat sampling (following Szigeti et al., 2016; Larson et al., 2018), creating a more complete species richness list for each site. This allowed us to better characterize plant establishment, and the success of the seed mix.

We observed a higher frequency of blooming species in mid- and late-summer, suggesting greater nectar availability during those times. The relatively low frequency of early season nectar resources suggests that managers should consider including more early blooming species in seed mixes for new plantings and enhance existing conservation lands with these species. While monarchs need nectar resources during both the breeding and migration periods within our study geography, more early-blooming species may be especially important for monarchs arriving from an energy-intensive northward migration (Alonso-Mejia et al., 2011).

Our study sites were planted with a wide range of blooming plant species (194 species across all sites). Similar to milkweed, the establishment rates of these plants were variable and speciesspecific. Some species grew in all or most sites in which they were planted (Rudbeckia hirta, Ratibida pinnata) while others grew in very few (Astragalus canadensis, Symphyotrichum novae-angliae). Other species had high colonization success (establishing in sites where they were not planted). The colonization success of certain species (such as Dalea purpurea and Rudbeckia hirta) may give reason to reduce them in future seed mixes with the expectation that they may appear on their own, especially if their seeds are costly. However, though some species may have higher establishment success across projects, we stress the importance of diversity in conservation grasslands; a diverse group of blooming plants provide nectar resources throughout the growing season, supply host plants for a suite of insects, and are more ecologically resilient (Naeem and Li, 1997; Tilman, 1997; Timberlake et al., 2019).

Though forb seeding rate and blooming plant frequency were not significantly correlated in multivariate models, the sample size for our seed rate analyses was small. More than half of our sites reported seeds in bulk or seedlings or did not have seeding information available. For two planted species in our study, a positive correlation between frequency and seeding rate was observed (Ratibida pinnata, Astragalus canadensis), suggesting that planting more seeds of these species may lead to a greater abundance at a site. Our study does not present enough information to identify site or species characteristics that affect overall forb frequency, and therefore more research is needed to determine those effects.

We did not observe an effect of burn frequency or forb seeding rate on blooming plant frequency or establishment rate. However blooming plant establishment rate responded to seed mix forb diversity, site size, and planting season. Overall, the highest establishment rates were observed at larger sites planted in the fall, when fewer species were included in the seed mixes. However, there were a number of interactions between these variables. Almost half of the sites in our study sample $(n=25)$ were planted 1-3 years prior to sampling, and these sites tended to have more diverse seed mixes. Because prairie species may take many years to establish, younger sites may not have had a chance to establish as fully as those seeded a decade or more ago, and establishment rate might still increase through time on those sites. Furthermore, higher diversity seed mixes may include species that are more difficult to establish, whereas low-diversity seed mixes may be more likely to include those known to have high establishment success. Diverse seed mixes are valuable if they may yield a fuller array of native prairie species; further research into rates of establishment for various species may assist future conservation efforts.

Fall planted sites had higher establishment rates than sites planted in summer. Fall plantings are favored by many managers in this region to ensure that seeds are cold-stratified prior to the first growing season (Kurtz, 2001), and our findings suggest that this is a good strategy. However, because this was not a randomized experimental design, we recommend continued investigation regarding the efficacy of seeding seasons.

\section{Monarch Use of Sites}

Monarch eggs, larvae, or adults were observed at most sites, suggesting that they provided suitable monarch habitat. Because monarch population estimates were well below historical averages during the study period (Rendon-Salinas et al., 2018), observed monarch densities across sites were also very low, making it difficult to detect any relationships between site characteristics and monarch numbers. More data are needed to better understand how relevant site characteristics (milkweed density, blooming plant richness and abundance) might impact monarch use (Leone et al., 2019).

Adult monarchs were observed nectaring from 31 blooming plant species, confirming that many blooming plant species on conservation grasslands provide nutritional resources for adult monarchs. While we noted that Monarda fistulosa was the most commonly utilized nectar plant, it was also commonly encountered on our sites, so we cannot make conclusions about monarch nectar plant preference.

\section{CONCLUSION}

Conservation grasslands represent an important source of existing and potential monarch habitat (Thogmartin et al., 2017a) and our study demonstrates that they provide milkweed in 
abundance; milkweed was observed at nearly every site and at densities much higher than previously estimated for similar grasslands (Thogmartin et al., 2017a). In a landscape drastically transformed by agriculture and development, this conserved habitat is critical for supporting monarchs and other wildlife.

The quality of habitat varied across sites, with a diverse suite of species at some, and few at others. Continued research on a larger sample of sites will further our understanding of the relationship between seeding and management practices and habitat responses across conservation grasslands. Other factors such as landscape context, weather during establishment, and soil characteristics could play a role in the establishment, colonization, and abundance of milkweed and nectar plants (Grman et al., 2015; Kaul and Wilsey, 2019), but these analyses were beyond the scope of our study.

Through the course of this study, multiple landowners suggested that many of the sites were managed for pollinators, and thus were likely to have better habitat resources than other similarly categorized sites. Management actions included manual or chemical weed removal and mowing, targeting species such as wild parsnip (Pastinaca sativa), thistles (Cirsium spp.), and buckthorn (Rhamnus spp.). Such actions were conducted with the intent of benefiting the native prairie plants, but due to a lack of spatial and temporal data on the extent of the actions, we were unable to determine their effects on the plant community. More detailed tracking by land managers can help to inform future conservation effectiveness studies to illustrate the benefits of these practices.

Our study required detailed information on seed mixes, seeding methods, and management actions. Ongoing studies will benefit from cooperation with landowners and managers who keep detailed records of management actions and who are open to sharing their practices with researchers. The protocols we used were prototypes for the Integrated Monarch Monitoring Program (IMMP), which monitors monarch habitat and monarch use throughout the North American breeding range (Cariveau et al., 2019a). The IMMP is an effective tool for addressing these questions. We encourage future researchers, landowners, and conservation practitioners to participate in the IMMP in order to build a more robust dataset for addressing questions relating to the effectiveness of their conservation practices. Ultimately, these data will lead to more efficient and effective conservation for monarchs and other pollinators.

\section{REFERENCES}

Agrawal, A. A., and Inamine, H. (2018). Mechanisms behind the monarch's decline. Science 360, 1294-1296. doi: 10.1126/science.aat5066

Alonso-Mejia, A. A., Rendon-Salinas, E., Montesinos-Patino, E., and Brower, L. P. (2011). Use of lipid reserves by monarch butterflies overwintering in Mexico: implications for conservation. Ecol. Appl. 7, 934-947. doi: 10.1890/10510761(1997)007[0934:uolrbm]2.0.co;2

Bates, D., Maechler, M., Bolker, B., and Walker, S. (2015). Fitting linear mixedeffects models using lme4. J. Stat. Softw. 67, 1-48. doi: 10.18637/jss.v067.i01

Baum, K. A., and Mueller, E. K. (2015). "Grassland and roadside management practices affect milkweed abundance and opportunities for monarch recruitment,", in Monarchs in a Changing World: Biology and Conservation of an Iconic Butterfly, eds K. S. Oberhauser, K. R. Nail, and S. Altizer, (Ithaca, NY: Cornell University Press), 197-202.

\section{AUTHOR CONTRIBUTIONS}

KO, WC, LL, and KK designed the study. LL and KK performed the research. $\mathrm{KO}, \mathrm{WC}$, and $\mathrm{AC}$ advised the project. LL, CS, KK, and $\mathrm{AC}$ led the data analysis. All authors contributed to the development and writing of the manuscript.

\section{FUNDING}

This work was supported by the USDA's Natural Resources Conservation Service under agreement number 68-7482-16-532, the Monarch Joint Venture, and the Environmental Defense Fund.

\section{ACKNOWLEDGMENTS}

We thank several parties for assistance throughout this study; the Wisconsin Department of Natural Resources, US Fish and Wildlife Service, USDA's Natural Resource Conservation Service, Pheasants Forever Farm Bill Biologists, and Prairie Restorations, Incorporated assisted with identifying potential study sites. Melissa Martin helped identify sites, identify research targets, and served as liaison for the NRCS. Wayne Thogmartin and Diane Larson provided analytical support, and Karen Tuerk provided technical and database assistance. We thank Nicholas Haas, Madeline Esterl, Nicole Biagi, Maisong Lee, Lizzy Lincoln, Alexander Jack, Wesley Marchand, Maud Prineas, Rachel Olson, Tyler Zolczynski, and Evan Carlson for their hard work collecting data and for their dedication to the project. We would like to give a final and very special thanks to the landowners who agreed to be part of this study. Their passion and dedication to conservation is critically important in a time of drastic landscapelevel change.

\section{SUPPLEMENTARY MATERIAL}

The Supplementary Material for this article can be found online at: https://www.frontiersin.org/articles/10.3389/fevo.2020.00013/ full\#supplementary-material

Bowles, M. L., and Jones, M. D. (2013). Repeated burning of eastern tallgrass prairie increases richness and diversity, stabilizing late successional vegetation. Ecol. Appl. 23, 464-478. doi: 10.1890/12-0808.1

Brower, L. P., Taylor, O. R., Williams, E. H., Slayback, D. A., Zubieta, R. R., and Ramirez, M. I (2012). Decline of monarch butterflies overwintering in Mexico: is the migratory phenomenon at risk? Insect Conserv. Divers. 5, 95-100. doi: 10.1111/j.1752-4598.2011.00142.x

Cariveau, A. B., Anderson, E., Baum, K. A., Hopwood, J., Lonsdorf, E., Nootenboom, C., et al. (2019a). Rapid assessment of roadsides as potential habitat for monarchs and other pollinators. Front. Ecol. Evol. 7:386. doi: 10. 3389/fevo.2019.00386

Cariveau, A. B., Holt, H. L., Ward, J. P., Lukens, L., Kasten, K., Thieme, J., et al. (2019b). The integrated monarch monitoring program: from design to implementation. Front. Ecol. Evol. 7:167. doi: 10.3389/fevo.2019. 00167 
Carter, D. L., and Blair, J. M. (2012). High richness and dense seeding enhance grassland restoration establishment but have little effect on drought response. Ecol. Appl. 22, 1308-1319. doi: 10.1890/11-1970.1

Commision for Environmental Cooperation (2017). Monitoring Monarch Butterflies and Their Habitat Across North America: Inventory and Monitoring Protocols and Data Standards for Monarch Conservation. Available at: http://www3.cec.org/islandora/en/item/11763-monitoring-monarchbutterflies-and-their-habitat-across-north-america-inventory-en.pdf (accessed December 31, 2018).

Dickson, T. L., and Busby, W. H. (2009). Forb species establishment increases with decreased grass seeding density and with increased forb seeding density in a Northeast Kansas, U.S.A., experimental prairie restoration. Restor. Ecol. 17, 597-605. doi: 10.1111/j.1526-100X.2008.00427.x

Elzinga, C. L., Salzer, D. W., and Willoughby, J. W. (1998). Measuring and Monitoring Plant Populations. Denver, CO: Bureau of Land Management, doi: 10.1016/j.mechmat.2007.03.006

Englert, J. M. (2007). A Simplified Guide to Understanding Seed Labels. Maryland Plant Materials Technical Note No. 2. Beltsville, MD: USDA-NRCS National Plant Materials Center, 1-3.

ESRI, (2011). ArcGIS Desctop. Redlands, CA: Environmental Systems Research Institute.

Evetts, L. L., and Burnside, O. C. (1972). Germination and seedling development of common milkweed and other species. Weed Sci. 20, 371-378. doi: 10.1017/ s004317450003589x

Grant, T. J., Parry, H. R., Zalucki, M. P., and Bradbury, S. P. (2018). Predicting monarch butterfly (Danaus plexippus) movement and egg-laying with a spatially-explicit agent-based model: the role of monarch perceptual range and spatial memory. Ecol. Modell. 374, 37-50. doi: 10.1016/j.ecolmodel.2018.02.011

Grman, E., Bassett, T., Zirbel, C. R., and Brudvig, L. A. (2015). Dispersal and establishment filters influence the assembly of restored prairie plant communities. Restor. Ecol. 23, 892-899. doi: 10.1111/rec.12271

Haan, N. L., and Landis, D. A. (2019). Grassland disturbance increases monarch butterfly oviposition and decreases arthropod predator abundance. Biol. Conserv. 233, 185-192. doi: 10.1016/j.biocon.2019.03.007

Hartzler, R. G. (2010). Reduction in common milkweed (Asclepias syriaca) occurrence in Iowa cropland from 1999 to 2009. Crop Prot. 29, 1542-1544. doi: 10.1016/j.cropro.2010.07.018

Hartzler, R. G., and Buhler, D. D. (2000). Occurrence of common milkweed (Asclepias syriaca) in cropland and adjacent areas. Crop Prot. 19, 363-366. doi: 10.1016/S0261-2194(00)00024-7

Houck, M. (2009). Understanding Seeding Rates, Recommended Planting Rated and Pure Live Seed. Plant Materials Technical Note No. 11. Alexandria, LA: USDA-NRCS.

Johnston, M. K., Lambruschi, M. P., Hasle, E. M., and Lewis, A. D. (2019). Estimating milkweed (Asclepias spp.) abundance under existing and userdefined scenarios in four metropolitan areas. Front. Ecol. Evol. 7:210. doi: 10. $3389 /$ fevo.2019.00210

Kasten, K., Stenoien, C., Caldwell, W., and Oberhauser, K. S. (2016). Can roadside habitat lead monarchs on a route to recovery? J. Insect Conserv. 20, 1047-1057. doi: 10.1007/s10841-016-9938-y

Kaul, A. D., and Wilsey, B. J. (2019). Monarch butterfly host plant (milkweed Asclepias spp.) abundance varies by habitat type across 98 prairies. Restor. Ecol. 27, 1274-1281. doi: 10.1111/rec.12993

Kinkead, K. E., Harms, T. M., Dinsmore, S. J., Frese, P. W., and Murphy, K. T. (2019). Design implications for surveys to monitor monarch butterfly population trends. Front. Ecol. Evol. 7:195. doi: 10.3389/fevo.2019.00195

Kurtz, C. (2001). A Practical Guide to Prairie Reconstruction. Iowa, IA: University of Iowa Press.

Lark, T. J., Salmon, M., and Gibbs, H. K. (2015). Cropland expansion outpaces agricultural and biofuel policies in the United States. Environ. Res. Lett. 10:044003. doi: 10.1088/1748-9326/10/4/044003

Larson, D. L., Bright, J. B., Drobney, P., Larson, J. L., Palaia, N., Rabie, P. A., et al. (2011). Effects of planting method and seed mix richness on the early stages of tallgrass prairie restoration. Biol. Conserv. 144, 3127-3139. doi: 10.1016/j. biocon.2011.10.018

Larson, D. L., Bright, J. B., Drobney, P., Larson, J. L., and Vacek, S. (2017). Persistence of native and exotic plants 10 years after prairie reconstruction. Restor.Ecol. 25, 953-961. doi: 10.1111/rec.12521
Larson, D. L., Viste-Sparkman, K., Esser, R., Larson, J. L., Drobney, P., and Ahlering, M. (2018). Developing a framework for evaluating tallgrass prairie reconstruction methods and management. Ecol. Restor. 36, 6-18. doi: 10.3368/ er.36.1.6

Leone, J. B., Larson, D. L., Larson, J. L., Pennarola, N., and Oberhauser, K. (2019). Adult monarch (Danaus plexippus) abundance is higher in burned sites than in grazed sites. Front. Ecol. Evol. 7:435. doi: 10.3389/fevo.2019. 00435

Majewska, A. A., Sims, S., Wenger, S. J., Davis, A. K., and Altizer, S. (2018). Do characteristics of pollinator-friendly gardens predict the diversity, abundance, and reproduction of butterflies? Insect Conserv. Divers. 11, 370-382. doi: 10. 1111/icad.12286

Middleton, E. L., Bever, J. D., and Schultz, P. A. (2010). The effect of restoration methods on the quality of the restoration and resistance to invasion by exotics. Restor. Ecol. 18, 181-187. doi: 10.1111/j.1526-100X.2008. 00501.x

Naeem, S., and Li, S. (1997). Biodiversity enhances ecosystem reliability. Nature 390, 507-509. doi: 10.1038/37348

Oberhauser, K. S. (2004). "Overview of monarch breeding biology," in The Monarch Butterfly: Biology and Conservation, eds K. S. Oberhauser, and M. J. Solensky, (Ithaca, NY: Cornell University Press), 3-7.

Oberhauser, K. S., Prysby, M. D., Mattila, H. R., Stanley-Horn, D. E., Sears, M. K., Dively, G., et al. (2001). Temporal and spatial overlap between monarch larvae and corn pollen. Proc. Natl. Acad. Sci. U.S.A. 98, 11913-11918. doi: 10.1073/ pnas. 211234298

Pleasants, J. (2017). Milkweed restoration in the Midwest for monarch butterfly recovery: estimates of milkweeds lost, milkweeds remaining and milkweeds that must be added to increase the monarch population. Insect Conserv. Divers. 10, 42-53. doi: 10.1111/icad.12198

Pleasants, J., and Oberhauser, K. (2012). Milkweed loss in agricultural fields because of herbicide use: effect on the monarch butterfly population. Insect Conserv. Divers. 6, 135-144. doi: 10.1111/j.1752-4598.2012.00196.x

Pleasants, J., Zalucki, M. P., Oberhauser, K. S., Brower, L. P., Taylor, O. R., and Thogmartin, W. E. (2017). Interpreting surveys to estimate the size of the monarch butterfly population: pitfalls and prospects. PLoS One 12:e0181245. doi: 10.1371/journal.pone. 0181245

R Core Team (2018). R: A Language and Environment for Statistical Computing. Vienna: R Foundation for Statistical Computing.

Rendon-Salinas, E., Martinez-Meza, F., Martinez-Pacheco, A., and Cruz-Piña, M. (2018). Superficie Forestal Ocupada por las Colonias de Hibernacion de la Mariposa Monarca en Mexico Durante Diciembre de 2017. World Wildlife Fund Mexico Report. Available at: http://awsassets.panda.org/downloads/ 2017_Monitoreo_Mariposa_Monarca_en_Mexico_2017-2018.pdf (accessed December 30, 2018).

Samson, F., and Knopf, F. (1994). Prairie conservation in North America. BioScience 44, 418-421. doi: 10.2307/1312365

Semmens, B. X., Semmens, D. J., Thogmartin, W. E., Wiederholt, R., López-ho, L., Diffendorfer, J. E., et al. (2016). Quasi-extinction risk and population targets for the Eastern, migratory population of monarch butterflies (Danaus plexippus). Sci. Rep. 6:23265. doi: 10.1038/srep23265

Stenoien, C., Nail, K. R., and Oberhauser, K. S. (2015). Habitat productivity and temporal patterns of monarch butterfly egg densities in the Eastern United States. Ann. Entomol. Soc. Am. 108, 670-679. doi: 10.1093/aesa/ sav054

Stenoien, C., Nail, K. R., Zalucki, J. M., Parry, H., Oberhauser, K. S., and Zalucki, M. P. (2016). Monarchs in decline: a collateral landscape-level effect of modern agriculture. Insect Sci. 25, 528-541. doi: 10.1111/1744-7917. 12404

Szigeti, V., Körösi, Á, Harnos, A., Nagy, J., and Kis, J. (2016). Comparing two methods for estimating floral resource availability for insect pollinators in seminatural habitats. Ann. Soc. Entomol. Fr. 52, 289-299. doi: 10.1080/00379271. 2016.1261003

Thogmartin, W. E., López-Hoffman, L., Rohweder, J., Diffendorfer, J., Drum, R., Semmens, D., et al. (2017a). Restoring monarch butterfly habitat in the Midwestern US: "all hands on deck". Environ. Res. Lett. 12, 074005. doi: 10. 1088/1748-9326/aa7637

Thogmartin, W. E., Wiederholt, R., Oberhauser, K., Drum, R. G., Diffendorfer, J. E., Altizer, S., et al. (2017b). Monarch butterfly population decline in North 
America: identifying the threatening processes. R. Soc. Open Sci. 4:170760. doi: $10.1098 /$ rsos. 170760

Tilman, D. (1997). Community invasibility, recruitment limitation, and grassland biodiversity. Ecology 78, 81-92. doi: 10.1890/0012-9658(1997)078[0081:cirlag] 2.0.co; 2

Timberlake, T. P., Vaughan, I. P., and Memmott, J. (2019). Phenology of farmland floral resources reveals seasonal gaps in nectar availability for bumblebees. J. Appl. Ecol. 56, 1585-1596. doi: 10.1111/1365-2664. 13403

Venables, W. N., and Ripley, B. D. (2002). Modern Applied Statistics with S. New York, NY: Springer.
Conflict of Interest: The authors declare that the research was conducted in the absence of any commercial or financial relationships that could be construed as a potential conflict of interest.

Copyright (c) 2020 Lukens, Kasten, Stenoien, Cariveau, Caldwell and Oberhauser. This is an open-access article distributed under the terms of the Creative Commons Attribution License (CC BY). The use, distribution or reproduction in other forums is permitted, provided the original author(s) and the copyright owner(s) are credited and that the original publication in this journal is cited, in accordance with accepted academic practice. No use, distribution or reproduction is permitted which does not comply with these terms. 